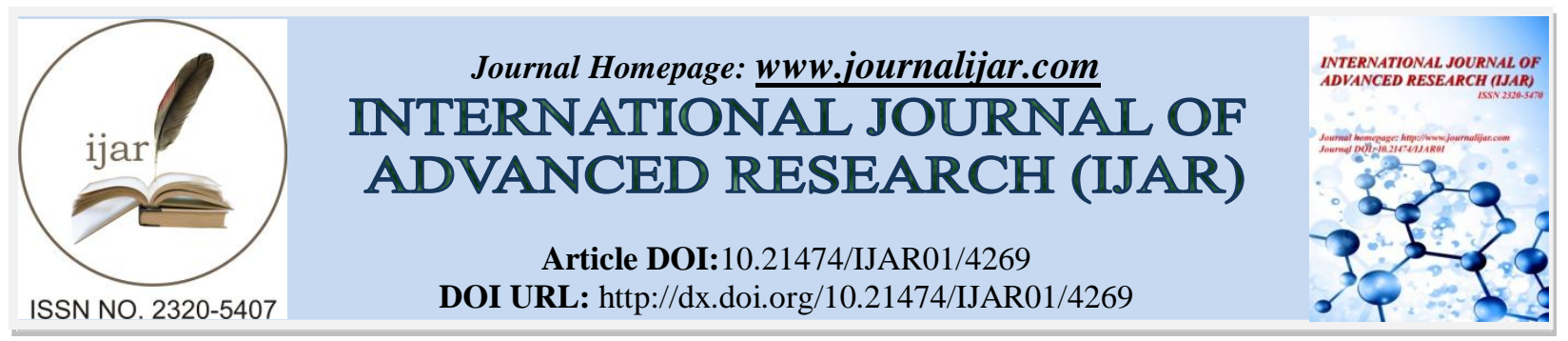

RESEARCH ARTICLE

\title{
IN VITRO ANTIMICROBIAL ACTIVITY OF NEW SUBSTITUTED 1,3,4-OXADIAZOLE DERIVATIVES.
}

Maryam Kouhkan ${ }^{1}$, Fatemeh Karimi ${ }^{2},{ }^{*}$ Ali Souldozi ${ }^{2}$ and Jalil Rashedi ${ }^{3}$.

1. Young Researchers and Elite Club, Urmia Branch, Islamic Azad University, Urmia, Iran.

2. Faculty of science, Urmia Branch, Islamic Azad University, Urmia, Iran.

3. Department of laboratory Sciences, School of Paramedicine, Tabriz Universityof Medical Sciences, Tabriz, Iran.

\section{Manuscript Info}

[........................

Manuscript History

Received: 27 March 2017

Final Accepted: 30 April 2017

Published: May 2017

Key words:

Oxadiazole; Antimicrobial Activity;

Antibacterial Activity; Antifungal

Activity; Minimum Inhibitory

Concentration

\section{Abstract}

Background: The need of new antimicrobial agents is justified because more microorganisms are being resistance to the currently available antibacterial drugs and this is bringing alarming threat to public health and causing growing concern among people across the globe. 1,3,4-Oxadiazole have shown a wide spectrum of antimicrobial activity. Some of the marketed drugs also possessed this heterocyclicmoiety.

Objectives: We have previously synthesized new series of (5-aryl1,3,4-oxadiazol-2-yl)(pyridin-2-yl)methanol derivatives (4a-4d) in fairly high yields. Here, we evaluated the antimicrobial activity of these derivatives against the following microorganisms: Staphylococcus epidermidis ATCC14990, Bacillus cereus PTCC 1015 ,Pseudomonas aeruginosa ATCC 27853, Staphylococcus aureus ATCC 25923, Escherichia coli ATCC 25922, Candida tropicalis PTCC 5028and Candida albicans ATCC10239.

Materials and Method: The broth macrodilutionand well agar diffusion methods were used for determination of inhibition zoom(IZ) and minimum inhibitory concentration (MIC) during preliminary evaluation of antimicrobial activity.

Results: All of the synthesized compounds exhibited promising antibacterial activity against Staphylococcus aureus and Staphylococcus epidermidis.

Conclusions: In this study, data suggest that compound (4a-4d) is a potent antibacterial compound with excellent MICs and acceptable selectivity index against Staphylococcal infections.

Copy Right, IJAR, 2017,. All rights reserved.

\section{Implication:}

Methicillin-resistant Staphylococcus aureus (MRSA) are a serious global public-health concern, as MRSA has become broadly resistant to many classes of antibiotics. We disclose herein the discovery of a new class of non- $\beta$ lactam antibiotics, the oxadiazoles, which inhibit Staphylococcus species. 
The discovery of new substances with proven antimicrobial activity is the current study goal of various researchers. Usage of synthetic products has grown considerably in the past few years due to processing agility, and capability of going through previous chemical modifications in order to enhance its biological activity. Widespread careless use of antimicrobials has made the number of resistant microorganisms rise significantly, thus demanding more efficient drugs to fight them.

Compounds containing 1,3,4-oxadiazole rings have a broad biological activity spectrum including antibacterial (1), antifungal (2), analgesic (3), anti-inflammatory (4), antiviral(5), anticancer(6), antihypertensive(7), anticonvulsant (8), and anti-diabetic properties(9). They have also attracted interest in medicinal chemistry as surrogates (bioisosteres) for carboxylic acids, esters and carboxamides (10). Two examples of compounds containing the 1,3,4-oxadiazole unit currently used in clinical are Raltegravir(11), antiretroviral drug(12) and Zibotenta(13) an anticancer agent (14).In recent years, a number of new 1,3,4-oxadiazole derivatives as antibacterial agents have been reported (15). The main modifications of these compounds were focused on the naphthyloxymethyl groups. In our previous study, we synthesized (5-aryl-1,3,4-oxadiazol-2-yl)(pyridin-2-yl)methanol, under mild conditions in a one-pot reaction to afford four novel (5-aryl-1,3,4-oxadiazol-2-yl)(pyridin-2yl)methanol derivatives in good yields (16).

\section{Objectives:}

As synthesis and evaluation of antimicrobial activity is an important part of our research program (17-19); herein, we have evaluated antibacterial and antifungal activity of these derivatives against gram positive (Staphylococcusaureus, Staphylococcus epidermidis, Bacillus cereus), gram negative (Pseudomonas aeruginosa, Escherichia coli) bacteria and fungal (Candida albicans and Candida tropicalis).

\section{Material and Methods:}

\section{Chemistry:}

A group of (5-aryl-1,3,4-oxadiazol-2-yl)(pyridin-2-yl)methanol derivatives (4a-d)were synthesized using previously published methods. Briefly, solution of $\mathrm{N}$-isocyaniminotriphenyphosphorane (1) and 2-pyridinecarbaldehyde (2) in $\mathrm{CH}_{2} \mathrm{Cl}_{2}$ was added dropwise to a solution of a carboxylic acid (3) in $\mathrm{CH}_{2} \mathrm{Cl}_{2}$ at room temperature over 15 min. The mixture was stirred for $12 \mathrm{~h}$. The solvent was removed under reduced pressure and the viscous residue was purified by flash column chromatography (Scheme 1).<smiles>C[C@@H](C(=O)O)c1cccc(C(O)C2=NN=C3OC=CC=CC=C2O[Al+2]3)n1</smiles>

\begin{tabular}{|c|c|}
\hline & $\mathbf{A r}$ \\
\hline $4 \mathrm{a}$ & $4-\mathrm{Br}-\mathrm{Ph}$ \\
\hline $4 \mathrm{~b}$ & $3-\mathrm{CH}_{3}-\mathrm{Ph}$ \\
\hline $4 \mathrm{c}$ & $5-\mathrm{Naphthalen}$ \\
\hline $4 \mathrm{~d}$ & 4- $\mathrm{CH}_{3}-\mathrm{Ph}$ \\
\hline
\end{tabular}

Scheme 1:- Synthesis of (5-aryl-1,3,4-oxadiazol-2-yl)(pyridine-2-yl)methanol derivatives.

\section{Antibacterial Activity:}

Agar Diffusion Method-Individual compounds Solutions:

Antibacterial activity of synthesized compounds were tested against several gram positive and gram negative bacteria including: Escherichia coli ATCC 25922, Pseudomonas aeruginosa ATCC 27853, Bacillus cereus PTCC 1015, Staphylococcus aureus ATCC 25923 and Staphylococcus epidermidis ATCC14990.These microorganisms were chosen because they are commonly isolated pathogens from hospitalized patient with intestinal ailments, blood and skin infections. All microorganisms were obtained from Urmia University of Medical Sciences. 
The standardization of each bacterial inoculum was done following the National Committee for Clinical Laboratory Standards (NCLS). Briefly, each bacterial strain inoculated into Mueller Hinton broth (MHB; Oxoid) was incubated to a turbidity equivalent to $0.5 \mathrm{McFarland}$ units. Bacterial strains were incubated for 12 hours at $35^{\circ} \mathrm{C}$ to achieve the turbidity of $0.5 \mathrm{McFarland}$ units. A standardized bacterial inoculum containing $5 \times 10^{5} \mathrm{cfu} / \mathrm{mL}$ (forming units per millimeter) colony were used for antibacterial screening. The antibacterial activity of the prepared compounds were screened using the well diffusion method (20).In short, each compound was dissolved in DMSO and a solution with $1 \mathrm{mg} / \mathrm{ml}$ concentration was prepared. $200 \mathrm{ml}$ of Muller Hinton Agar (MHA, Merck, Germany) was melted over a boiling water bath then was stabilized at $45^{\circ} \mathrm{C}$ and aseptically seeded with $100 \mu 1$ inoculum, containing $0.5 \times 10^{6}$ cells $/ \mathrm{ml}$ of bacteria, transferred into a sterile Petri dish. Wells were made in agar using a sterile glass tube and $50 \mu 1$ of compounds was transferred to each well. $50 \mu 1$ of DMSO was inoculated into another well as a negative control. The antibacterial activity of compounds was determined by measuring the zones around each well against defined bacteria after incubation for $24 \mathrm{~h}$. Ceftizoxime and Ciprofloxacin used with the same method as standard antibacterial agents. Experiments were performed at least three times and the moral values were selected.

\section{Broth dilution Method:}

In the next step antimicrobial activity of compounds was evaluated by broth dilution method(21). The aim of this method is determining the lowest concentration of an antimicrobial agent that, under defined conditions, inhibits the visible growth of the tested organism which is considered by the lack of turbidity in a broth medium. Minimum Inhibitory Concentration (MIC) values are used in order to determining the susceptibility of the organism to antibiotics and new antibacterial agents. In this study sterile glass test tubes containing Muller Hinton Broth((MHB, Merck, Germany) was used.10 $\mu \mathrm{L}$ of inoculum contained $1.5 \times 10^{6}$ C.F.U $/ \mathrm{ml}$ of tested microorganism was added to each test tube. Minimum Bactericidal Concentration (MBC) values were determined by sub culturing of the tested tubes on agar media that do not contain the antibacterial agent. The MBC is determined by detecting the lowest concentration of compounds that reduces the viability of the bacterial inoculums by $\geq 99.9$. Ceftizixime and ciprofloxacin (Sigma,Aldrich,US) were used with the same method as standard antimicrobial agents.

\section{Antifungal Activity:}

The in vitro antifungal activity of the (5-aryl-1,3,4-oxadiazol-2-yl)(pyridin-2yl)methanol derivatives (4a-4d) were evaluated against standardized clinically important fungi, including: Candida tropicalisandCandida albicans ATCC 10239. The antifungal assay was performed by the agar well diffusion and Broth macrodilution methods(22, 23). In brief, fungal suspension containing $1.5 \times 10^{6} \mathrm{cell} / \mathrm{mL}$ of yeast was swabbed and spread on Sabouraud dextrose agar (SDA, (Merck, Germany). A well was cut at the centre of each inoculated medium using a standard cork borer of 6 $\mathrm{mm}$ diameter and $100 \mu \mathrm{g} / \mathrm{mL}$ of the test compounds dissolved in DMSO were introduced into the wells. Following addition of solutions, these Petri plates were incubated for $48 \mathrm{~h}$ at a temperature of $28 \pm 2^{\circ} \mathrm{C}$ and then growth and zones of inhibition (in $\mathrm{mm}$ ) were recorded.

In the next steps the Minimum Inhibitory concentrations (MICs) were determined by broth dilution technique.TheSabouraud dextrose broth(SDB, (Merck, Germany) tubes containing test compounds were serially diluted. The $48 \mathrm{~h}$ grown cultures of fungi was inoculated in each tube. The tubes were incubated at room temperature for $24 \mathrm{~h}$. The lowest concentration required to arrest the growth of fungi was regarded as MIC. To get the minimum fungicidal concentration (MFC), a loopful was taken from the MIC tubes and streaked on SDA plates. The growth was observed after incubation at $37^{\circ} \mathrm{C}$ at $24 \mathrm{~h}$. The lowest concentration which showed no growth was recorded as MFC(24).

\section{Antibacterial Activity:}

Herein, we have evaluated antibacterial and antifungal activity of some of previously prepared 1,3,4-oxadiazol derivatives containing 4-bromophenyl(4a), 3-methylphenyl(4b), Naphthalene (4c) and 4-methylphenyl (4d) moieties in their structure (Scheme 1). Results of the inhibition zone values for synthesized compounds against tested bacteria presented in Table 1 . According to Figure 2 all of the compounds showed high antibacterial activity against S.epidermidis and S.aureus. No zone of inhibition was seen around the well containing DMSO (Figure1). 


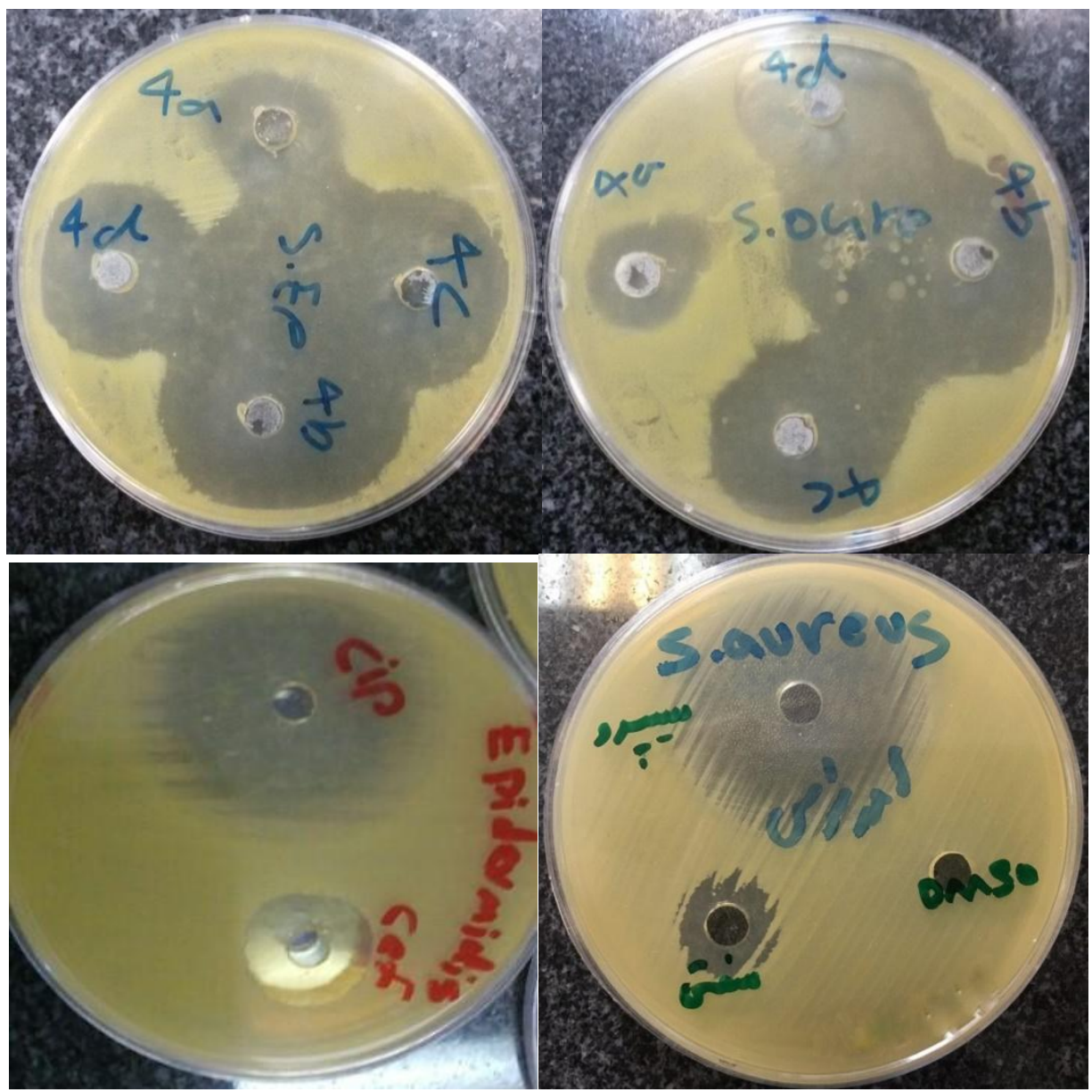

Fig1:Inhibition zone of compounds against Staphylococcus aureus and Staphylococcus epidermidis in $1 \mathrm{mg} / \mathrm{ml}$ concentration

Table 1: Antibacterial activity of 5-aryl-1,3,4-oxadiazol derivatives by Agar well diffusion $(1 \mathrm{mg} / \mathrm{ml})$

\begin{tabular}{|l|c|c|c|c|c|}
\hline$N$ & $\begin{array}{c}\text { S.aureus } \\
\text { ATCC.25923 }\end{array}$ & $\begin{array}{l}\text { S.epidermidis } \\
\text { ATCC.14990 }\end{array}$ & $\begin{array}{l}\text { Mean zone of } \\
\text { inhibition(mm) } \\
\text { P.aeruginosa } \\
\text { ATCC.27853 }\end{array}$ & $\begin{array}{l}\text { E.coli } \\
\text { ATCC. } 25922\end{array}$ & $\begin{array}{l}\text { Bacilluscereus } \\
\text { PTCC 1015 }\end{array}$ \\
\hline 4a & $17 \pm 0.6$ & $17 \pm 0.28$ & NA & $13 \pm 0.23$ & NA \\
\hline 4b & $27 \pm 0.16$ & $30 \pm 0.8$ & NA & $14 \pm 0.8$ & NA \\
\hline 4c & $24 \pm 0.18$ & $27 \pm 0.23$ & NA & $14 \pm 0.18$ & NA \\
\hline 4d & $25 \pm 0.8$ & $27 \pm 0.18$ & NA & $14 \pm 0.23$ & NA \\
\hline Ceftizoxim & $15 \pm .03$ & $14 \pm 0.8$ & $20 \pm 0.8$ & $17 \pm 0.3$ & $11 \pm 0.3$ \\
\hline Ciprofloxacin & $34 \pm 0.6$ & $35 \pm 0.8$ & $42 \pm 0.6$ & $44 \pm 0.3$ & $34 \pm 0.8$ \\
\hline
\end{tabular}

NA: No activity

\section{Determination of MIC:}

The minimum Inhibitory concentrations (MIC) of tested compounds (4a-4d) are shown in (Table2). Our results revealed that all compounds were active against S.aureus and S.epidermidis.The MBC of compounds was the same or three fold higher than the corresponding MIC results. 
Table 2:- Minimum inhibitory concentrations of synthesized compounds $(\mu \mathrm{g} / \mathrm{mL})$ for tested bacteria

\begin{tabular}{|l|c|c|c|c|c|}
\hline $\mathrm{N}$ & $\begin{array}{c}\text { S.aureus } \\
\text { ATCC.25923 }\end{array}$ & $\begin{array}{l}\text { MIC }(\mu \mathrm{g} / \mathrm{ml}) \\
\text { S.epidermidis } \\
\text { ATCC.14990 }\end{array}$ & $\begin{array}{c}\text { P.aeruginosa } \\
\text { ATCC.27853 }\end{array}$ & $\begin{array}{l}\text { E.coli } \\
\text { ATCC.25922 }\end{array}$ & $\begin{array}{l}\text { Bacilluscereus } \\
\text { PTCC 1015 }\end{array}$ \\
\hline 4a & 62 & 31 & 1000 & 500 & 1000 \\
\hline 4b & 15 & 250 & 1000 & 250 & 1000 \\
\hline 4c & 32 & 250 & 1000 & 500 & 1000 \\
\hline 4d & 32 & 500 & 1000 & 500 & 1000 \\
\hline Cefizoxim & 62 & 50 & 62 & 32 & 50 \\
\hline Ciprofloxacin & 0.029 & 15 & 0.23 & 0.23 & 15 \\
\hline
\end{tabular}

\section{Antifungal Activity:}

The antifungal activity of (5-aryl-1,3,4-oxadiazol-2-yl)(pyridin-2-yl) methanol derivatives (4a-4d) against two kinds of pathogenic fungi was investigated and summarized in Table3. Figure 2 presents the results for antifungal activities of all the title compounds.
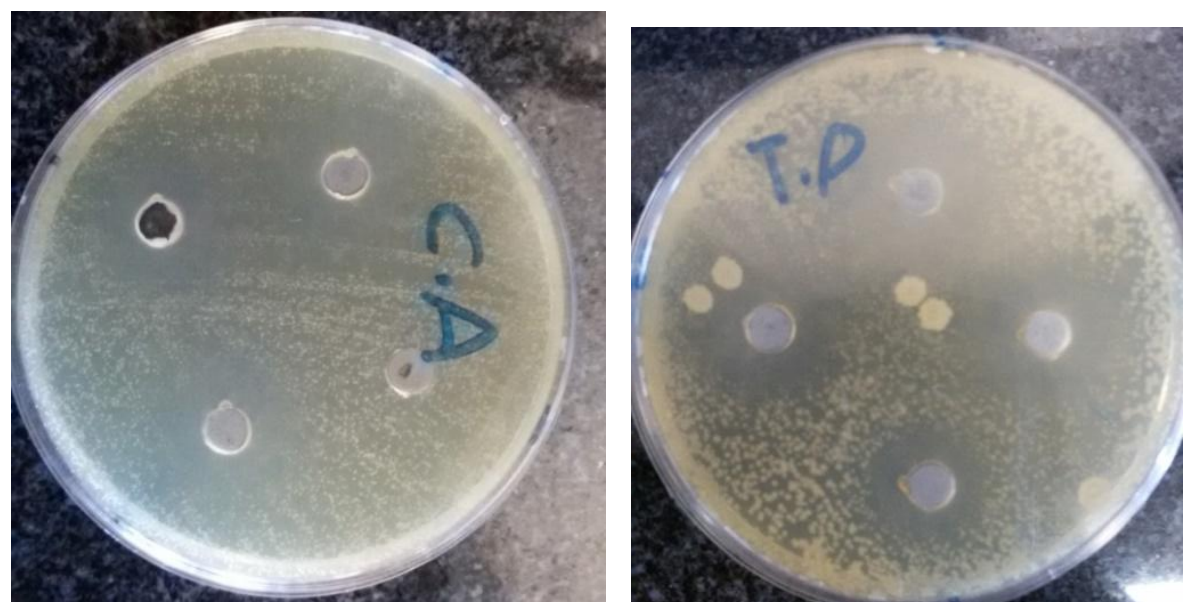

Fig.2:- Inhibition zone of compounds against Candida tropicalisand Candida albicans in $1 \mathrm{mg} / \mathrm{ml}$ concentration.

Table 3:- Antifungal activity of 5-aryl-1,3,4-oxadiazol

\begin{tabular}{|c|c|c|c|c|}
\hline \multirow[b]{2}{*}{$\mathrm{N}$} & \multicolumn{2}{|c|}{ Candida albicans } & \multicolumn{2}{|c|}{ Candida tropicalis } \\
\hline & $\mathrm{IZ}(\mathrm{mm})$ & $\operatorname{MIC}(\mu \mathrm{g})$ & $\mathrm{IZ}(\mathrm{mm})$ & $\mathrm{MIC}(\mu \mathrm{g})$ \\
\hline $4 a$ & $16 \pm 0.8$ & $500 \pm 0.6$ & $16 \pm 0.18$ & $500 \pm 0.8$ \\
\hline $4 \mathrm{~b}$ & $15 \pm 0.12 \quad 500 \pm 0.23$ & & $20 \pm 0.8 \quad 250 \pm 0.26$ & \\
\hline $4 c$ & $16 \pm 0.23$ & $500 \pm 0.8$ & $17 \pm 0.6$ & $500 \pm 0.6$ \\
\hline $4 d$ & $\mathrm{~N}$ & $\mathrm{~N}$ & $500 \pm 0.34$ & \\
\hline
\end{tabular}

\section{Discussion:-}

In vitro antibacterial activity of the synthesized compounds was performed against Staphylococcusaureus, Staphylococcus epidermidis, Bacillus cereusPseudomonasaeruginosa and Escherichia coli. The activity potentials were qualitatively assessed by the presence or absence of inhibition zones, zone diameters, MIC and MBC values. As shown in Table 1 the minimum Inhibitory concentrations (MIC) of tested compounds revealed that all compounds were active against S.oureus and S.epidermidis (MIC $=15-62 \mu \mathrm{g} / \mathrm{mL}$ ) and exhibited excellent antibacterial activity in comparison to ceftizoxim $(\mathrm{MIC}=6.25 \mu \mathrm{g} / \mathrm{mL})$ however they showed poor activity compared with Ciprofloxacin (MIC $=0.39 \mu \mathrm{g} / \mathrm{mL}$ ). From the screening data, The Oxadiazol having Naphthalenesubstituent(4b) showed better activity against E. coli ( $\mathrm{MIC}=15 \mu \mathrm{g} / \mathrm{ml}$ ). The lowest activity of compounds (4a-4d) was observed against Bacillus cereus and P.aeruginosa $(\mathrm{MIC}=1000 \mu \mathrm{g} / \mathrm{ml})$. A comparative study of MIC values indicates that the inhibitory activity of these compounds on Gram positive bacteria is better than on Gram negative bacteria. Antifungal potential of synthesized compounds (4a-4d) were evaluated according to their zone of inhibition against two pathogens and the MIC and MFC values were determined in the range of 250 
to $1000 \mu \mathrm{g} / \mathrm{ml}$. The results revealed that all the compounds are potent antimicrobials against Candida tropicalisandCandida albicans. The zones inhibition diameters and the MIC values indicate that all synthesized compounds 4a-d have moderate inhibition activities. Compound (4c)showed the maximum activity with MIC value of $250 \mu \mathrm{g} / \mathrm{ml}$ against Candida albicansand Candida tropicalis but the (5-Phenyl-1,3,4-oxadiazol-2-yl)(pyridin-2yl)methanol (4d) showed no antifungal activity against Candida albicans. MFC values for title compounds were similar to MIC results. As a result of our previous work, the antimicrobial activity of 2-aryl-1,3,4-oxadiazole against Gram-positive bacteria was proved (18). The data found in the literature matching our research claims that the compounds with halogen substituent are the most efficient against Gram-positive bacteria, particularly against $\mathrm{S}$. aureus [23, 24].A comparison between the results of this study and our previous report, revealed that all of our 1,3,4oxadiazol derivatives with pyridine ring at the C-2 position on the linker of 1,3,4-oxadiazol, can be identified as the most promising antibacterial agents against S.oureus and S.epidermidis with a MIC value of 7.5 to $15 \mu \mathrm{g} / \mathrm{mL}$. In this study, data suggest that compound $(4 \mathrm{a}-4 \mathrm{~b})$ is a potent antibacterial compound with excellent MICs and acceptable selectivity index against Staphylococcal infections. Furthermore the easy workup, high yield, and short reaction times makes the method a useful addition for preparing modern pharmaceutical synthetics.

\section{References:-}

1. Selvakumar K, Anandarajagopal K, Rajamanickam V, Ajaykumar T V, Jesindha B. 5-(2-aminophenyl)-1,3,4oxadiazole-2(3h)thionederivatives:synthesis,characterization and antimicrobial evaluation. Int. J. Pharm. Sci. Rev. Res.2011;6(1): 64-67

2. Dalia H. S. Synthesis, Characterization, Anti-Bacterial and Anti-Fungal Activities of New Quinoxaline1,4-di-NOxide Derivatives. Int. J. Org. Chem. 2013; 3: 65-72

3. Asif H, Moham A. Synthesis of novel 1,3,4-oxadiazole derivatives and their biological properties. Acta Pharm. 2009; 59: 223-233

4. Ali, A., Mousavi, Z., Tajik, M., Assarzadeh, MJ.,Shafiee, A., (2014). Synthesis, analgesic and anti inflammatory activities of new methylimidazolyl-1,3,4-oxadiazoles and 1,2,4-triazoles. Daru. 2014; 22 (1): 2234

5. Tashfeen A, Shahid H, Najim A.A, Roberta L, Paolo L.C. In vitro antitumor and antiviral activities of new benzothiazole and 1,3,4-oxadiazole-2-thione derivatives. Acta Pharm. 2008; 58: 135-149

6. Sanmati K. J, Arvind K. Y, Pragya N. 3D QSAR Analysis on Oxadiazole Derivatives as Anticancer Agents. Int. J. Pharm. Sci. Drug Res. 2011; 3(3): 230-235

7. Rakesh S, Anuja Ch. various approaches for synthesis of 1,3,4-oxadiazole derivatives and their pharmacological activity. World J. Pharm. Pharm. Sci. 2014; 3(10): 1474-1505

8. Mohammad S.Y and Mohammad W.A. Synthesis And Anticonvulsant Activity Of Substituted Oxadiazole And Thiadiazole Derivatives. ActaPoloniaePharmaceutica. 2009; 66 (4): 393-397

9. NouraddinH,SoodehS,Mohamad B.D, Mohammad H, Mehdi Khans et all. Synthesis and Antidiabetic Evaluation of Benzenesulfonamide Derivatives. Iran. J. Pharm. Res. 2013, 12 (2): 325-330

10. Soltis MJ, Yeh HJ, Cole KA, Whittaker N, Wersto RP, Kohn EC. Identification and characterization of human metabolites of CAI [5-amino-1-1(4'-chlorobenzoyl- 3,5dichlorobenzyl)-1,2,3-triazole- 4-carboxamide). Drug MetabDispos. 1996; 24(7):799-806

11. Vincenzo S, AlessiaP,FabioB,BenedettaC,Monica D and et al. Discovery of Raltegravir, a Potent, Selective Orally Bioavailable HIV-Integrase Inhibitor for theTreatment of HIV-AIDS Infection. J. Med. Chem. 2008; 51: 5843-5855

12. Chama Sh and Sanchit S. Biologically Active Oxadiazo. Asian J.Res.Pharm.Sci. 2015; 5(4): 227-233

13. Mohammad A,Taqi A. Kh,Meraj A Kh. 1,2,4-oxadiazole nucleus with versatile biological applications. IJPSR. 2014; 5(07): 303-316.

14. Catalin V. M, Elena F, Peter G. J, HeikoF,Gerhard K, Heiner F and et al. Synthesis and characterization of novel bioactive1,2,4-oxadiazole natural product analogsbearing the $\mathrm{N}$-phenylmaleimide and $\mathrm{N}$ phenylsuccinimide moieties. Beilstein J. Org. Chem.2013;9:2202-2215

15. Ming-Xia S, Chang-Ji Z, Xian-Qing D, Zhi-Yu W and Hu-Ri P. The Synthesis and Anti-Bacterial Activities of N -carboxymethylRhodanines. 2014; Med chem. 2014; 4(5): 441-448

16. Ali S. Efficient one-pot three-component reaction for the synthesis of (5-aryl-1,3,4-oxadiazol-2-yl)(pyridin-2yl)methanol derivatives. J. Chem. Res.. 2015; 39:177-179

17. Maryam K, NimaH.j, Ali S, Minoo Z and Narges D. Green synthesis and preliminary pharmacological evaluation of three-substituted thiazide derivatives as antibacterial agents.JCPR. 2015; 8(5): 149-154

18. Fatemeh K, Ali S and Nima H.J. One-pot synthesis of 2-aryl-1,3,4-oxadiazole derivatives as potential antibacterial agents. JCPR. 2015; 7(10): 1028-1033 
19. Maryam K, NimaH.j, Ali S, Minoo Z and Narges D. Solvent free synthesis of alkyl 2-(dialkylamino)phenylthiazole-5carboxylates derivatives and in vitro antimycobacterial activity of these compounds against Mycobacterium smegmatis. JCPR. 2015; 7(7): 338-345

20. Chenielle D, Lois R, Alison N, Sylvia M, John L, Mohammed A. Antibacterial and antifungal analysis of crude extracts from the leaves of Callistemon viminalis. Journal of medical and pharmaceutical science.2009; 3(1): 17.

21. FereshtehS,Akbar S. A,Saman S, Reza Z, Javad A.K, Kiarash G. Antibacterial activity

22. Of Glycyrrhizaglabra against oral pathogens:aninvitro. Avicenna J. Phytomed. 2012; 2(3): 118-124

23. Moses I, MaduagwuU,Osazuwa E. Evaluation of the Antifungal Activity of Aqueous and Alcoholic Extracts of Six Spices. Am. J. Plant Sci. 2016; 7:118-125

24. Mohitosh Bi, MdAjijur R, Hajerakhand Anwar U. In vitro Antibacterial and Cytotoxic

25. Activities of Two Compounds Isolated from Streptomyces sp. MBS. Bangladesh Pharm. J. 2012; 15 (1): 13-16

26. Ali A, Aicha H, Said G, Radouane M, BouchraCh and Lalla I. Reveal antifungal activities of essential oils from LavanduladentataL. a way of valuing the arganeraie. Pharma Chem. 2016; 8(3):249-253

27. Samija M, Kemal D, Elma V, AMAR O, Dženita S, Davorka Z. synthesis of biscoumarin derivatives as antimicrobial agents. Asian J Pharm Clin Res. 2013; 6(3): 132-134. 